ISSN 0103-5150

Fisioter. Mov., Curitiba, v. 30, n. 2, p. 207-217, Apr./June 2017

Licenciado sob uma Licença Creative Commons

DOI: http://dx.doi.org/10.1590/1980-5918.030.002.A001

(c) (i)

\title{
Reported dyspnea and fatigue using different scales during the physical effort in COPD
}

\author{
Percepção de dispneia e fadiga na DPOC por \\ diferentes escalas durante o esforço físico
}

\section{Alaís Camargo Corcioli ${ }^{[a]}$, Bruna Varanda Pessoa-Santos ${ }^{[a, b]}$, Glaucia Nency Takara ${ }^{[a]}$, Valéria Amorim Pires Di Lorenzo ${ }^{[a]}$, Mauricio Jamami ${ }^{[a]^{*}}$}

[a] Universidade Federal de São Carlos (UFSCar), São Carlos, SP, Brazil

[b] Universidade do Sagrado Coração (USC), Bauru, SP, Brazil

\section{Abstract}

Introduction: Therapy choice and its progression for patients with Chronic Obstructive Pulmonary Disease (COPD) should be based on their symptoms and clinical condition according to reports of dyspnea and fatigue. Therefore patient-reported scales have presented a key role during the communication with the patient. Objective: To verify if patients with COPD prefer the Modified Borg Scale (MBS), Visual Analogue Scale (VAS), Glasses Scale (GS), Faces Scale (FS) or Ratings of Perceived Exertion (RPE) during the six-minute walk test(6MWT), and to compare and correlate the scales with each other, with peripheral oxygen saturation (SpO2) and heart rate (HR). Methods: 28 patients with COPD (50\% had mild to moderate COPD and $50 \%$ had severe to very severe) were evaluated by a respiratory and cognitive assessment. Additionally, they performed the 6MWT, in which the scales were applied simultaneously (random order) and patients reported their preference in the end of the test. Results: $57 \%$ of patients were illiterate or presented incomplete primary education and most of them (67\%) chose the FS or GS. Significant positive correlations were observed between instruments for both dyspnea and fatigue in the end of the 6MWT, which the strongest was between MBS and

*ACC: BS, e-mail: alaiscorcioli@gmail.com BVPS: PhD, e-mail: brunavpessoa@gmail.com GNT: MS, e-mail: nencyjp@hotmail.com VAPD: PhD, e-mail: vallorenzo@ufscar.br MJ: PhD, e-mail: jamami@ufscar.br 
FS $(r=0.95)$. Nevertheless, there was no correlation between the scales and SpO2 and HR. Conclusion: As the majority of patients preferred pictured to numerical scales we suggest their use as a resource for therapeutic evaluation; MBS might be replace by FS, even though they have different scores and not scaled proportionally. However, this change must be carefully considered because there is the risk of dubious interpretation.

Keywords: Perception. Language. Signs and Symptoms. COPD.

\section{Resumo}

Introdução: A escolha terapêutica e sua progressão ao intervir em pacientes com Doença Pulmonar Obstrutiva Crônica (DPOC) devem ser baseadas nos seus sintomas e quadro clínico, considerando relatos de dispneia e fadiga; assim, escalas perceptivas assumem papel fundamental na comunicação com o paciente. Objetivo: Verificar se pacientes com DPOC preferem a Escala de Borg Modificada (EBM), Escala Visual Analógica (EVA), Escala de Copos (EC), Escala de Faces (EF) ou Ratings of perceived exertion (RPE) durante o teste de caminhada de seis minutos (TC6), bem como comparar e correlacionar as escalas entre si e com saturação periférica de oxigênio e frequência cardíaca. Métodos: Foram avaliados 28 pacientes com DPOC (50\% deles com DPOC leve a moderada e 50\% com DPOC grave a muito grave) por meio de uma avaliação respiratória e cognitiva, além do TC6, onde aplicou-se as escalas simultaneamente em ordem aleatória, posteriormente o paciente indicou sua escala preferida. Resultados: $57 \%$ dos pacientes eram analfabetos ou com ensino fundamental incompleto e a maioria (67\%) elegeu a EF ou EC. Correlações positivas significantes foram observadas interinstrumentos tanto para dispneia quanto para fadiga nos membros inferiores ao final do TC6, sendo mais forte entre EBM $e$ EF $(r=0,95)$. Entretanto, não foi observada correlação significante entre as escalas e a $\mathrm{SpO}_{2}$ e $\mathrm{FC}$. Conclusão: Como a maioria dos pacientes preferiu escalas caricaturizadas às numéricas, sugerimos inseri-las como recurso de avaliação terapêutica; é possível substituir a EBM pela EF, ainda que tenham escores diferenciados e não escalonados proporcionalmente, atentando-se ao risco de interpretação dúbia.

Palavras-chave: Percepção. Linguagem. Sinais e Sintomas. DPOC.

\section{Introduction}

The clinical symptoms of chronic obstructive pulmonary disease (COPD) includes persistent cough with variable respiratory secretion production and mostly chronic and progressive fatigue and dyspnea (1). Additionally, exercise tolerance may be affected by extra-pulmonary changes $(1,2)$.

Dyspnea is a subjective experience of uncomfortable respiratory sensations (3) that intensifies the disease, since it is incapacitating and anxiety-inducer in patients (1). Moreover, dyspnea may be understood and quantified by who experiences it (4). Fatigue is an unpleasant and distressing symptom, which is referred as a mild tiredness or exhaustion (5). This symptom negatively impacts in COPD patients' functional performance and quality of life (5-7).

In order to offer an adequate therapeutic intervention, the understanding regarding the severity of the disease $(8,9)$ and the symptoms intensity is essencial (10). Even though this is individual for each patient, they might not recognize their signs, maybe because of the lack of body consciousness or poor understanding about COPD progression. Therefore, in the attempt of objectively assessing the subjective interrelationship of physiology and emotions (6), studies $(3,4,6,9$ - 18) have suggested the use of patient-reported scales, which are a quick, less complex and relatively costless method that provides information based in patient's self assessment.

The most employed patient-reported scales during exercise are the modified Borg Scale (MBS) and the visual analogical scale (VAS) $(10,12,14,19)$. Nevertheless, other scales are available, as examples, the ratings of perceived exertion (RPE) (15) and pictured scales, such as the Whaley \& Wong glasses scale (GS) and the Wong-Baker faces scale (FS) (18). The latter two scales are indicated in the assessment of pain in children and 
elders, who not-unusually present difficulties in communication and in interpreting numbers.

Considering the relevance of patient-physiotherapist communication and the importance of the assessment during the clinical follow-up, the aim of this study was to verify if patients with COPD have a preferred scale among the above cited ones (MBS, RPE, VAS, GS e FS) during the six-minute walk test (6MWT) and to compare their variations during effort, as well as the physiological changes due the test. Moreover, another aim was to verify the existence of correlations between scales and with peripheral oxygen saturation (SpO2) and heart rate (HR), which were obtained in the end of the test.

\section{Methods}

Studied individuals

Thirty five male or female patients were assessed, who were 50 years old or older and presented clinical and spirometrical COPD diagnosis. They had mild to very severe obstruction (1), were clinically stable, without history of infections or symptom exacerbations in the previous two months and were referred to pulmonary rehabilitation (PR) in the Special Unity of Respiratory Physiotherapy from the Federal University of São Carlos.

Individuals with impaired walking or current smokers were excluded from the study. In addition, those with cognitive impairment assessed by the Mini-Mental State Examination (MMSE) (20) were also excluded, since this function is necessary to report a symptom or affliction (21).

Seven patients were excluded for reasons like impaired walking $(n=1)$, clinical exacerbation during the assessment period ( $\mathrm{n}=3)$, current smoking $(\mathrm{n}=1)$, low MMSE $(\mathrm{n}=2)$. The final sample was 28 patients with COPD.

\section{Experimental Procedure}

Patients' assessments were conducted in three consecutive days in the morning. On the first day, a general and respiratory physical exam, analysis of recent (maximum one month) medical spirometry (all conducted by the same pneumologist, who used the same reference equations) and the cognitive screening using the MMSE, which was completed by the patient in a private room and with the same previously-trained assessor for all patients.

Dyspnea and lower limbs (LLs) fatigue assessments occurred during 6MWTs conducted in the second and third days. The choice in using the 6MWT was due the fact it is a simple and low-cost submaximum test. Furthermore, 6MWT correlates with COPD prognostic indices (22).

The corridor structure followed the 6MWT standards (23), and each two minutes of the test, dyspnea and fatigue were assessed in order to better achieve the proposed aim. Patients with COPD were instructed and incentivised to walk as far as they could during six minutes, using standardized phrases each minute. Additionally, the test followed a cadence-free protocol (23).

The first test was conducted to allow the volunteers to know the procedure and the scales, removing the learning effect (24). The greatest walked distance in the 6MWT was used in the statistic analysis. Furthermore, the walked distance percentage in this test was calculated using the equation [(walked distance in the $6 \mathrm{MWT} \div$ predicted distance) ${ }^{* 100]}$ (25).

Sp02 and HR were measured using a portable pulse oxymeter (NONIM ${ }^{\circledR} 2500$, Plymouth, Minnesota, USA), which was carried by the volunteers using an appropriate backpack. In addition, SpO2 and HR were registered at rest, in the second, fourth and sixth minutes, as well as in the first third and sixth recovery minutes. Arterial blood pressure was measured at rest, immediately after the test and in the recovery time; the individual was in the seated position and the measure was done using a mercury sphygmomanometer $\left(\right.$ Oxigel $^{\circledR}$, São Paulo, SP, Brazil). The maximum predicted HR was calculated by the equation 220-age (years). All patients was informed about the study and signed a consent form. The study was approved by the ethics committee from the institution (approval number 439/2009).

\section{Patient-reported scales}

RPE, MBS, VAS, GS and FS were the five adopted patient-reported scales. The latter two scales were modified replacing the word pain for the words dyspnea and LLs fatigue. RPE was developed in 1970 by Borg and it is a 15-level scale, in which the lowest values was six, representing "no effort" and the highest value was 20 , representing "maximum effort". The scale represents HR variation between $60-200 \mathrm{bpm}$, considering that there is a correlation between HR and workload (15). 
The MBS was also developed by Borg twelve years after the RPE, and its aim was to simplify the score attached to the anchored expressions, in order to be used by the less-educated population, which may not be familiarized with technical and mathematical expressions. In this scale, symptom intensity is displayed progressively in a 0-10 score, which represents the "absence of dyspnea" and "maximum dyspnea" respectively (16).

The VAS is represented by a $10 \mathrm{~cm}$ horizontal line; the initial point indicates the absence of symptoms and the final one, maximum intensity. The distance between the initial point and the marker done by the patient indicates dyspnea or fatigue intensity (17).

The GS is represented by five glasses, in which the first is empty (absence of symptom) and the last is a full glass (maximum symptom intensity). Differently, FS is composed by six faces, which their expressions modifies from happy to a crying face according to the symptom intensity (18).

All scales were explained by the same assessor and patients answered them simultaneously, in a random order in each 6MWT, before (at rest), during (each two minutes) and in the end of the test (sixth minute) and after the effort (sixth recovery minute), except the VAS, that was used only at rest, in the end of test and in the recovery, since it required the patient to fill a marker. In the end of the 6MWT, the volunteers were asked about which scale they thought were more appropriate for them, using the question "which scale you thought was easier to tell me how was your dyspnea and leg fatigue?".

\section{Data Analysis}

Data was analysed using GraphPad InStat version 3.05 (GraphPad Software, San Diego, California, USA) e Statistical Package for Social Sciences for Windows version 16.0 (SPSS Inc, Chicago, IL) statistical packages. It was expressed as mean and standard deviation, percentage, median and range (minimum-maximum). Data distribution was verified with Shapiro-Wilk test. In order to compare the variations in $\mathrm{SpO}_{2}$ and $\mathrm{HR}$, repeated-measures ANOVA was used. The scores in the scales were compared using Friedman test and, when a difference was found, Dunn post hoc was used. Moreover, the Spearman correlation coefficient was used to analyse the correlations in the study. The adopted significance level was $\mathrm{p} \leq 0.05$.

\section{Results}

Twenty eight individuals concluded the study stages, and the majority of patients presented severe to very-severe obstruction (50\%).

The majority of participants (57\%) had low educational level (incomplete elementary school); however, in general, they presented high score in the MMSE. Considering the total score of 30 points, the illiterate participants presented a score of $22 \pm 4$ items; the scores of the participants with incomplete and complete elementary school was $26 \pm 2$ e $28 \pm 2$ points, respectively. The participants who completed high school presented a score of $27 \pm 2$ points and those with a graduation presented a score of $28 \pm 2$ points. The sample characteristics are displayed in Table 1.

Table $\mathbf{1}$ - Characteristics of the studied population

\begin{tabular}{lc}
\hline Variables & Results $^{\mathrm{a}}$ \\
\hline Age, years & $71 \pm 7$ \\
Weight, kg & $68.0 \pm 12.2$ \\
Height, cm & $170 \pm 10$ \\
BMI, kg/m² & $24.4 \pm 3.6$ \\
FEV1, \% predicted & $53 \pm 21$ \\
FEV1/FVC $\%$ & $56 \pm 14$ \\
Stage of COPD, $\mathrm{n}(\%)$ & \\
$\quad$ Mild & $2(7 \%)$ \\
$\quad$ Moderate & $12(43 \%)$ \\
$\quad$ Severe & $13(46 \%)$ \\
$\quad$ Very severe & $1(4 \%)$ \\
mMRC, $\mathrm{n}(\%)$ & \\
0 & $1(4 \%)$ \\
1 & $24(85 \%)$ \\
2 & $1(4 \%)$ \\
3 & $2(7 \%)$ \\
4 & - \\
Educational levels, $\mathrm{n}$ (\%) & \\
$\quad$ Illiterate & \\
Incomplete elementary & $2(7 \%)$ \\
school & $14(50 \%)$ \\
Complete elementary & \\
school & $2(7 \%)$ \\
High school & $3(11 \%)$ \\
Graduation & $7(25 \%)$ \\
MMSE Score & $27 \pm 3$ \\
\hline
\end{tabular}

Note: a Results expressed as mean \pm standard deviation or number (n) of the event followed by percentage. BMl: Body-mass index; FEV1 = Forced expiratory volume in the first second; FVC: Forced vital capacity; COPD: Chronic obstructive pulmonary disease; mMRC: modified Medical Research Council scale; MMSE: Mini-Mental State Examination. 
Regarding the preference for the instruments, one (4\%) voted in RPE scale, eight (29\%) chose the MBS, eight (29\%) preferred the GS while 11 individuals (38\%) elected the FS as the preferred. There was no vote to VAS scale. Summarizing, there was 19 votes for GS and FS against nine votes to RPE and MBS.

Considering these values, the majority of participants (67\%) preferred pictured scales than numeric scales and FS was indicated at least once in all educational levels
(Figure 1). There was an association between low educational level with pictured scales, since $64 \%$ of the votes for this scale came from patients with educational level equal or lower than complete elementary school.

In the 6MWT with the greatest distance, walked distance, $\mathrm{SpO}_{2}$ and $\mathrm{HR}$ were assessed (Table 2) and the delta of the scales in second, fourth and sixth minutes of the test and in the sixth minute of recovery are presented in Table 3, considering $\Delta=$ value in the desired moment — value at rest.

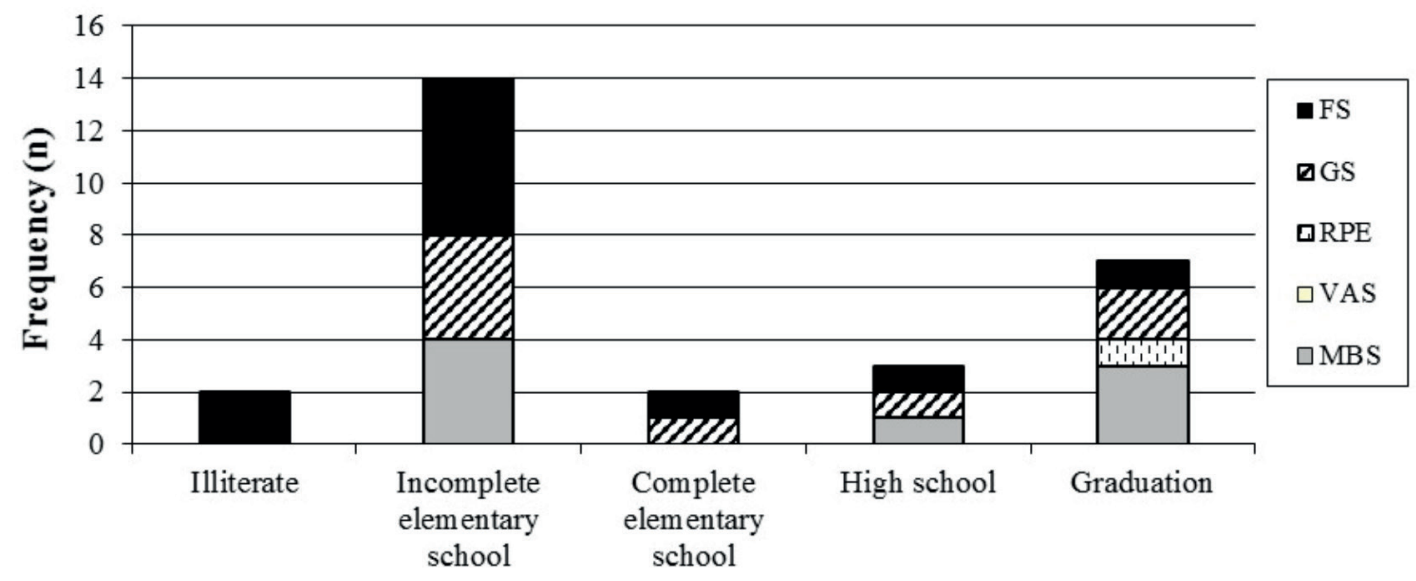

Educational levels

Figure 1 - Educational levels x Preference for the instruments

Note: MBS: Modified Borg Scale. RPE: Ratings of Perceived Exertion. VAS: Visual Analogical Scale. GS: Glasses Scale. FS: Faces Scale.

Table 2 - Walked distance and physiological variables in the 6MWT

\begin{tabular}{|c|c|c|c|c|c|}
\hline & \multicolumn{5}{|c|}{ Six-minute Walk Test (6MWT) } \\
\hline & Baseline & $2^{0}$ minute & $4^{0}$ minute & $6^{0}$ minute & Rec6 \\
\hline Variables ${ }^{\mathrm{a}}$ & & & & & \\
\hline WD-6MWT, m & & & & $429.7 \pm 133$ & \\
\hline $\begin{array}{l}\text { WD-6MWT, \% } \\
\text { predictedb }\end{array}$ & & & & $86.1 \pm 26.7$ & \\
\hline $\mathrm{SpO}_{2}, \%$ & $94 \pm 2$ & $91 \pm 3$ & $90 \pm 4$ & $91 \pm 4$ & $95 \pm 2$ \\
\hline $\begin{array}{l}\Delta \mathrm{SpO}_{2}, \% \\
\text { HRmax predicted, } \\
\text { bpm }\end{array}$ & $149 \pm 7$ & $-2.5 \pm 2.3$ & $-3.4 \pm 2.8$ & $-3.0 \pm 2.7$ & $1.2 \pm 1.4$ \\
\hline $\mathrm{HR}, \mathrm{bpm}$ & $79 \pm 12$ & $100 \pm 10$ & $105 \pm 12$ & $105 \pm 14$ & $81 \pm 9$ \\
\hline $\begin{array}{l}\text { HRmax, \% } \\
\text { predictedb }\end{array}$ & $53.1 \pm 8.6$ & & & $68.7 \pm 8.6$ & $54.8 \pm 8.9$ \\
\hline$\Delta \mathrm{HR}, \mathrm{bpm}$ & & $21 \pm 12$ & $26 \pm 13$ & $27 \pm 14$ & $2.5 \pm 6.4$ \\
\hline
\end{tabular}

Note: aResults expressed as mean \pm standard deviation. ${ }^{\mathrm{b} P e r c e n t a g e}$ of predicted values. Rec6: sixth recovery minute. WD-6MWT: Walked Distance in the 6MWT. $\mathrm{SpO}_{2}$ : peripheral oxygen saturation. HR: heart rate. HRmax: maximum heart rate. $\Delta$ : value in the desired time - baseline. 
Table 3 - Dyspnea and lower limbs fatigue measured by the studied scales during the 6MWT

\begin{tabular}{|c|c|c|c|c|c|}
\hline & \multicolumn{5}{|c|}{ Six-minute Walk Test (6MWT) } \\
\hline & Baseline & $2^{0}$ minute & $4^{0}$ minute & $6^{0}$ minute & Rec6 \\
\hline \multicolumn{6}{|l|}{ Dyspnea $^{a}$} \\
\hline MBS & $0(0-4)$ & $0.5(0-5)$ & $0.75(0-10)$ & $1.5(0-9)$ & $0(0-1)$ \\
\hline$\Delta$ & & $0.5(0-2)$ & $0.5(0-6)$ & $1(0-9)^{*}$ & $0(-3-1)$ \\
\hline RPE & $6(6-13)$ & $7(6-15)$ & $8(6-20)$ & $9(6-15)$ & $6(6-11)$ \\
\hline$\Delta$ & & $0(0-5)$ & $2(0-7)^{*}$ & $2(0-9)^{*}$ & $0(-3-5)$ \\
\hline VAS, mm & $0(0-37)$ & & & $13.5(0-98)$ & $0.75(0-28)$ \\
\hline$\Delta$ & & NA & NA & $10(73-0)$ & $0(-28-29)$ \\
\hline GS & $1(1-3)$ & $2(1-4)$ & $2(1-5)$ & $2(1-4)$ & $1(1-2)$ \\
\hline$\Delta$ & & $1(1-0)$ & $1(0-2)$ & $1(0-3)^{*}$ & $0(-1-1)$ \\
\hline FS & $0(0-3)$ & $1(0-4)$ & $1(0-5)$ & $2(0-4)$ & $0(0-2)$ \\
\hline$\Delta$ & & $0(0-2)$ & $1(0-3)$ & $1(0-4)^{*}$ & $0(-2-2)$ \\
\hline \multicolumn{6}{|c|}{ LLs fatigue ${ }^{a}$} \\
\hline MBS & $0(0-2)$ & $0.25(0-3)$ & $1(0-5)$ & $1(0-5)$ & $0(0-2)$ \\
\hline$\Delta$ & & $0(0-2)$ & $0.5(0-3)$ & $1(0-5)^{*}$ & $0(-2-2)$ \\
\hline RPE & $6(6-11)$ & $7(6-11)$ & $8(6-15)$ & $8(6-13)$ & $6(6-13)$ \\
\hline$\Delta$ & & $0(-2-3)$ & $1.5(0-5)^{*}$ & $2(-5-7)^{*}$ & $0(-5-7)$ \\
\hline VAS, mm & $0(0-9)$ & & & $11.5(0-56)$ & $1(0-33)$ \\
\hline$\Delta$ & & NA & NA & $12(43-0)$ & $0.5(-6-51)$ \\
\hline GS & $1(1-2)$ & $2(1-2)$ & $2(1-3)$ & $2(1-4)$ & $1(1-3)$ \\
\hline$\Delta$ & & $0(0-1)$ & $1(0-2)$ & $1(0-3)^{*}$ & $0(-1-2)$ \\
\hline FS & $0(0-1)$ & $0.5(0-3)$ & $1(0-3)$ & $2(0-4)$ & $0(0-3)$ \\
\hline$\Delta$ & & $0(0-2)$ & $1(0-3)$ & $1(0-4)^{*}$ & $0(-1-3)$ \\
\hline
\end{tabular}

Note: a Results are expressed as median (minimum - maximum). Rec6: sixth recovery minute. $\Delta$ : value in the desired time - baseline. MBS: Modified Borg Scale. RPE: Ratings of Perceived Exertion. VAS: Visual Analogical Scale (in millimeters). GS: Glasses Scale. FS: Faces Scale. $*$ : $p<0.05$; Friedman test with Dunn post hoc. NA: not applicable.

Table 4 - Spearman correlation coefficient between the five adopted patient-reported scales, peripheral oxygen saturation and heart rate in the sixth minute of 6MWT

\begin{tabular}{|c|c|c|c|c|c|}
\hline \multicolumn{6}{|c|}{ Dyspnea } \\
\hline & MBS & RPE & VAS & GS & FS \\
\hline RPE & $0.92^{*}$ & & & & \\
\hline VAS & $0.75^{\star}$ & $0.68^{*}$ & & & \\
\hline GS & $0.77^{\star}$ & $0.70^{*}$ & $0.65^{\star}$ & & \\
\hline FS & $0.95^{*}$ & $0.90^{*}$ & $0.75^{\star}$ & $0.83^{*}$ & \\
\hline Sp02 & 0.09 & 0.04 & 0.16 & 0.22 & 0.18 \\
\hline $\mathrm{HR}$ & -0.28 & -0.27 & -0.21 & -0.27 & -0.19 \\
\hline \multicolumn{6}{|c|}{ LLs fatigue } \\
\hline & MBS & RPE & VAS & GS & FS \\
\hline RPE & $0.85^{\star}$ & & & & \\
\hline VAS & $0.77^{*}$ & $0.53^{*}$ & & & \\
\hline GS & $0.84^{*}$ & $0.77^{\star}$ & $0.67^{*}$ & & \\
\hline FS & $0.89^{*}$ & $0.90^{*}$ & $0.66^{\star}$ & $0.89 *$ & \\
\hline $\mathrm{SpO}^{2}$ & 0.09 & -0.03 & 0.07 & 0.25 & 0.12 \\
\hline HR & -0.36 & -0.33 & -0.13 & -0.30 & -0.32 \\
\hline
\end{tabular}

Note: Spearman correlation coefficient. "Significant values $(p<0.0001)$. MBS: Modified Borg Scale. RPE: Ratings of Perceived Exertion. VAS: Visual Analogical Scale. GS: Glasses Scale. FS: Faces Scale. $\mathrm{SpO}_{2}$ : peripheral oxygen saturation. HR: heart rate. LLs: lower limbs. 
Eight patients presented oxygen dessaturation in 6MWT second minute, twelve in the fourth minute and 11 in the sixth minute, however, all patients completed the test and after six minutes of recovery, the $\mathrm{SpO}_{2}$ of all individuals was above $90 \%$. The changes in $\mathrm{SpO}_{2}$ and HR during the test, including recovery, were not considered as statistically significant.

Regarding the scales, positive $\Delta$ indicates the increase in dyspnea and fatigue; while values equal or less than zero are considered as symptom relief. All the described results shows that symptoms increased during the 6MWT, with a higher intensity in the end of the effort; in the sixth minute of walk, the change in LLs fatigue and dyspnea score was statistically significant for RPE, MBS, GS and FS. Symptom regression, indicated as a decrease in scales' scores, only occurred after the interruption of the effort. Moreover, this decrease was proportional to the recovery time and scores after the sixth recovery minute reached similar values to the rest. Therefore, patients' reports about their symptoms were analogue to the scales.

Considering the perceived effort, there was a moderate to strong positive correlation between instruments for both dyspnea and LLs fatigue in the end of the 6MWT. Nevertheless, there was no correlation between the scales and $\mathrm{SpO}_{2}$ and $\mathrm{HR}$ (Table 4).

\section{Discussion}

The main findings reveal that the majority of volunteers elected GS or FS as the easiest scales, demonstrating the preference for pictured scales. Communication relates and transmits knowledge; among other roles, it allows the social inclusion of sick individuals. Once established, stress, fear, distress, anxiety, sadness and depression are translated favouring the interaction between patient and therapists (26).

Effort scales are effective communication tools, and since they are practical and relatively cost-free, they are commonly used (27). Nevertheless, although scales may have similar goals, they are structurally different: even when positioned in a crescent order, they do not present the same increment proportions and they are asymmetrical as the quantity of notifications. Each scale may initiate in number zero, one or six which represent the absence of symptoms, and they may end in numbers five, ten or 20. RPE presents 15 choice possibilities, while MBS presents 12, VAS 101 possible scores (when assessed in milimeters),
GS five and FS six options. Therefore, the individuals must have more attention in quantifying their symptoms, as well as present cognitive activity to understand the complexity of the physiological events due to physical effort and associate them to the scores in each scale.

Words may fail when describing symptoms and, considering verbal scales with pre-determined terms, the same word may be used with different meanings and this does not implicate that people experiences the same feeling (17). Hence, a previous explanation is necessary with the purpose of enlighten the meaning of each score, using an accessible language according to the particularities of each patient.

By the means of consciousness and cognition, a symptom or affliction may be reported, focusing in the informs and sensorial stimulus (21). In the observational study of Campbell and colleagues (21), with 89 patients receiving palliative care and with imminence in the appearance of dyspnea due to the advance of the basal disease, the symptom was asked using the VAS; $54 \%$ of the patients were incapable of answering yes or no due to the consciousness level and, of the 41 respondents, only 20 were able to quantify using the scale, which demonstrate that the selfreport is associated to consciousness, cognition, and severity of the terminal illness, which requires great attention while dealing with palliative care, where symptoms may be ignored, under or over-treated.

MEEM results indicates that cognitive functions were preserved, which was relevant to achieve the main goal, even though the low educational level was the most prevalent. Diniz and colleagues (28) demonstrated that the scores lean to be higher to younger or more educated individuals, conversely, a desirable score was found in a homogeneous sample regarding age and with low educational level.

Hareendran and colleagues (29) assessed the capacity of MBS, VAS and one other numerical scale in verifying dyspnea during exercise among 11 patients with COPD, who were encouraged to quantify their experienced dyspnea during 24 hours after effort. Six patients (55\%) preferred the MBS, thus, authors concluded that its content is more valid to gather data about dyspnea, however, no pictured scale were used.

According to Borg (16), since there is no perfect scale, the most appropriate action is to select the scale depending on what one wants to assess, considering the instrument the patient consider being more familiar, simple and easy. 
The probability of a physiotherapist to treat illiterate patients, in their different types, increases when we consider that the demand of public services is, in its majority generated by people with low educational level, who seeks mostly ambulatory consultation (30). Since COPD is more prevalent in lower social levels (8), more studies should be conducted in this direction. The use of pictured scales may be a response to the illiterate patients in physiotherapy treatment problem, since they constitute a non-verbal way of expressing and interacting with other people (31). Its benefits are not restricted to this educational profile, but encompasses, in general, patients with COPD that in their clinical assessments have difficulties in symptoms self-assessments. A study, as an example, created the modified analogue-visual Borg scale to fit the characteristics of a low socio-economical level or illiterate population, this scale was compared to the MBS and presented strong correlation between their scores.

In clinical settings, MBS is the most used scale during exercise $(10,12,14,19)$ and to determine the training intensity of patients with COPD (8). Moreover, researchers (11) assessed its use during asthmatic crisis and obtained satisfactory results, therefore recommending MBS to the initial assessment of patients suffering with an asthmatic crisis, as well as their response to treatment. However, numeric scales, such as Borg scales, demand previous learning from the patients, so they can read, interpret and inform the number that correspond to the intensity of their symptom (13), which again is a problem.

VAS requires that patients mark the scale, which is not feasible during exercise. Moreover, seven patients inadequately marked the scale, with horizontal lines or outside the scale's limits. The finding of the present study corroborates with the ones from Hareendran and colleagues (29) in which none patients chose VAS to quantify their dyspnea, since they reported it was more confusing and difficult to mark than the other scales during exercise. However, these results disagree with the research from Grant and colleagues (32) in which VAS and MBS had their reliability assessed during a submaximum effort in young, healthy and active adults. They concluded that, although the scales presented similar patterns, VAS was more sensitive and reliable. The preference for the scales was not assessed. A study (3) with a similar population to the present study correlated several multidimensional (questionnaire) and unidimentional (scales) dyspnea assessment instruments, and they found moderate correlation between MBS and VAS during the 6MWT, but only VAS correlated with spirometrical values.

Recently, Lima and colleagues (33) assessed VAS (with captions) discriminating power to the exerciseinduced bronchial constriction level in asthmatic teenagers and children; they concluded that the accuracy of this scale increases proportionally to the decrease of the $\mathrm{FEV}_{1}$ after exercise, nevertheless, the predictive value of the scale was good when the percentage of the decrease in $\mathrm{FEV}_{1}$ is lower. A similar result was previously found by Mahler and colleagues (34) in an adult population with COPD. They compared three dyspnea assessment instruments during activities of daily living. These authors demonstrated that the more severe is the disease (lower $\mathrm{FEV}_{1}$ ), and consequently, greater pulmonary hyperinflation, the more intense dyspnea was reported.

Only one study (20) used GS to assess pain in elders, and none has adapted the scale to assess dyspnea or fatigue, this may have happened since pictured scale present imprecise intermediate points, generating doubts regarding the symptom intensity quantification, which was supported by the reports of some patients during the application of GS.

Even though a decrease in $\mathrm{SpO}_{2}$, increase in $\mathrm{HR}$ and of the five scales scores during effort, there was no correlation between the studied scales, $\mathrm{SpO}_{2}$ and HR, which might have happened due to the sample size or because the walking rhythm or the total walking distance that may have not be enough to induce a work overload. Another possible reason was patients presented difficults in interpret symptoms intensity during effort, even with preserved cognition.

Bucther and colleagues (35) demonstrated that there is an inverse correlation between muscle fatigue and dynamic hyperinflation in COPD. In the present study we verified that dyspnea reports were more intense than fatigue ones, whilst patients walked approximately $86 \%$ of the predicted without achieving the $70 \%$ of the maximum estimated HR, corroboration with Bucther and colleagues findings.

O'Donnell and colleagues (36), in their study, induced dyspnea in patients with COPD and healthy volunteers, and according to the effort intensity and the response to unpleasant stimuli, the emotional component of dyspnea individually varied, contributing to different clinical symptom expression and influence for health assistance. Furthermore, they 
also verified that among patients answers, "I am not receiving enough air" and "I am suffocating" were the best descriptions to translate the experience of respiratory discomfort.

The limitation of this study was the series of simultaneous questions in a 12 minutes interval, totalizing 62 answers for each 6MWT; this occurrence corroborates with a study (7) about fatigue frequency, duration and severity in patients with COPD that found a similar limitation as a result of a large questioning. They used the Fatigue Impact Scale (FIS) that is a multidimensional scale and is composed by 40 questions; even though it is considered as a simple and easy to apply scale, two patients referred that was hard to focus in the questions since FIS was too long, which lead to fatigue; thus, authors suggests the administration of short and less tiring questionnaires to this population.

Moreover, although verbally stimulated to maintain the walking rhythm, patients reduced the speed during the assessor approach. Other limitation was the fact that perception implicates in the recognition and interpretation of conscious sensorial stimuli and its meaning (10). In fact, the difficult in quantify a symptom implicates in the capacity of translating a subjective personal experience in a numerical parameter (19). Thereafter, several factors may influence the effort self-perception, which may be explained by physiological changes in $60 \%$ of the cases and psychological changes in $40 \%$. This fact makes effort perception occasional and circumstantial (4).

In patients with COPD, dyspnea may be secondary to a dynamic hyperinflation, neuro-mechanical dissociation, gas exchange abnormalities, respiratory muscle weakness, as well as cognitive, psychological (3), social and environmental influences (10). The same happens to fatigue, which is also composed by this multiple elements, such as cognition and psychosocial factors, and is not restricted to physical function $(5,7)$.

\section{Conclusion}

The scales used in this study presented statistical significance between each other, which was stronger between MBS and FS, which points out a possible interchange, since patients preferred a pictured scale to a numeric scale. However, the scores were different and were not staggered, and its interpretation may be dubious generating equivocated results.

A correlation between physiological variables and the scales was not found, nevertheless, more studies are required to establish the cut-off point in the pictured scales to determine when effort is submaximum or the highest probability of oxygen dessaturation. Thus, it would establish a safe interval of cardiorespiratory training.

Since the clinical assessment of symptoms is relevant in PR process, the choice about which scale is the most adequate to this population is important. Therefore, we suggest the introduction of pictured scales as a resource in the elaboration of treatment strategies of respiratory physiotherapy, as a result of a better acceptance between the studied individuals, as well as the affirmation that they are easier to interpret symptoms and do not require previous education.

\section{References}

1. Vestbo J, Hurd SS, Agustı AG, Jones PW, Vogelmeier C, Anzueto A, et al. Global Strategy for the Diagnosis, Management, and Prevention of Chronic Obstructive Pulmonary Disease: GOLD Executive Summary. Am J Respir Crit Care Med. 2013;187(4):347-65.

2. Dourado VZ, Tanni SE, Vale SA, Faganello MM, Sanchez FF, Godoy I. Manifestações sistêmicas na doença pulmonar obstrutiva crônica. J Bras Pneumol. 2006;32(2):161-71.

3. Camargo LACR, Pereira CAC. Dispneia em DPOC: além da escala modified Medical Research Council. J Bras Pneumol. 2010;36(5):571-8.

4. Campbell ML. Psychometric testing of a respiratory distress observation scale. J Palliat Med. 2008;11(1):44-50.

5. Wong CJ, Goodridge D, Marciniuk DD, Rennie D. Fatigue in patients with COPD participating in a pulmonary rehabilitation program. Int J Chron Obstruct Pulmon Dis. 2010;5:319-26.

6. Brandão MRF, Pereira MNN, Oliveira R, Matsudo VKR Percepção do esforço: uma revisão da área. R Bras Ci e Mov. 1989;3(1):34-40. 
7. Theander K, Unosson M. Fatigue in patients with chronic obstructive pulmonary disease. J Adv Nurs. 2004;45(2):172-7.

8. Langer D, Probst VS, Pitta F, Burtin C, Hendriks E, Schans CPVD, et al. Guia para prática clínica: Fisioterapia em pacientes com Doença Pulmonar Obstrutiva Crônica (DPOC). Rev Bras Fisioter. 2009; 13(3):183-204.

9. Brunetto AF, Paulin E, Yamaguti WPS. Comparação entre a Escala de Borg Modificada e a Escala de Borg Modificada Análogo Visual aplicadas em pacientes com DPOC. Rev Bras Fisioter. 2002;6(1):41-5.

10. Parshall MB, Schwartzstein RM, Adams L, Banzett RB, Manning HL, Bourbeau J, et al. An official American Thoracic Society Statement: Update on the mechanisms, assessment and management of dyspnea. Am J Respir Crit Care Med. 2012;185(4):435-52.

11. Cavallazzi TGL, Cavallazzi RS, Cavalcante TMC, Bettencourt ARC, Diccini S. Avaliação do uso da Escala Modificada de Borg na crise asmática. Acta Paul Enferm. 2005;18(1):39-45.

12. Sassi-Dambron DE, Eakin EG, Ries AL, Kaplan RM. Treatment of dyspena in COPD: A controlled clinical trial of dyspnea management strategies. Chest. 1995;107(3):724-9.

13. Mador MJ, Rodis A, Magalang UJ. Reproducibility of Borg scale measurements of dyspnea during exercise in patients with COPD. Chest. 1995;107(6):1590-7.

14. Bausewein C, Farquhar M, Booth S, Gysels M, Higginson IJ. Measurement of breathlessness in advanced disease: a systematic review. Respir Med. 2007; 101 (3):399-410.

15. Borg G. Perceived exertion as an indicator of somatic stress. Scand J Rehabil Med. 1970;2(2):92-8.

16. Borg GA. Psychophysical bases of perceived exertion. Med Sci Sports Exerc. 1982;14(5):377-81.

17. Aitken RC. Measurement of feelings using visual analogue scale. Proc R Soc Med. 1969;62(10):989-93.

18. Wong DL, Baker CM. Pain in children: comparison of assessment scales. Pediatr Nurs. 1988;14(1):9-17.

19. Crisafulli E, Clini EM. Measures of dyspnea in pulmonary rehabilitation. Multidiscip Respir Med. 2010; 5(3):202-10.
20. Lourenço RA, Veras RP. Mini-Exame do Estado Mental: características psicométricas em idosos ambulatoriais. Rev Saude Publica. 2006;40(4):712-9.

21. Campbell ML, Templin T, Walch J. Patients who are near death are frequently unable to self-report dyspnea. J Palliat Med. 2009;12(10):881-4.

22. Rodrigues SL, Viegas CAA. Estudo de correlação entre provas funcionais respiratórias e o teste de caminhada de seis minutos em pacientes portadores de doença pulmonar obstrutiva crônica. J Bras Pneumol. 2002;28(6):324-8.

23. American Thoracic Society Statement: Guidelines for the Six-Minute Walk Test. Am J Respir Crit Care Med. 2002;166(1):111-7.

24. Rodrigues SL, Mendes HF, Viegas CAA. Teste de caminhada de seis minutos: estudo do efeito do aprendizado em portadores de doença pulmonar obstrutiva crônica. J Bras Pneumol. 2004;30(2):121-5.

25. Soares MR, Pereira CAC. Teste de caminhada de seis minutos: valores de referência para adultos saudáveis no Brasil. J Bras Pneumol. 2011;37(5):576-83.

26. Mesquita RM. Comunicação não-verbal: relevância na atuação profissional. Rev Paul Educ Fis. 1997;11(2):155-63.

27. Graef FI, Kruel LFM. Frequência cardíaca e percepção subjetiva do esforço no meio aquático: diferenças em relação ao meio terrestre e aplicações na prescrição do exercício - uma revisão. Rev Bras Med Esporte. 2006;12(4):221-8.

28. Diniz BSO, Volpe FM, Tavares AR. Nível educacional e idade no desempenho no Miniexame do Estado Mental em idosos residentes na comunidade. Rev Psiq Clin. 2007;34(1):13-7.

29. Hareendran A, Leidy NK, Monz BU, Winnette R, Becker $\mathrm{K}$, Mahler DA. Proposing a standardized method for evaluating patient report of the intensity of dyspnea during exercise testing in COPD. Int J Chron Obstruct Pulmon Dis. 2012;7:345-55.

30. Ribeiro MAS, Barata RB, Almeida MF, Silva ZP. Perfil sociodemográfico e padrão de utilização de serviços de saúde para usuários e não-usuários do SUS - PNAD 2003. Ciênc. saúde coletiva. 2006;11(4):1011-22. 
31. Santos CCV, Shiratori K. A influência da comunicação não verbal no cuidado de enfermagem. Rev Bras Enferm. 2005;58(4):434-7.

32. Grant S, Aitchison T, Henderson E, Christie J, Zare S, McMurray J, Dargie H. A Comparison of the reproducibility and the sensitivity to change of visual analogue scales, Borg scales, and Likert scales in normal subjects during submaximal exercise. Chest. 1999;116(5):1208-17.

33. Lima PB, Santoro IL, Caetano LB, Cabral ALB, Fernandes ALG. Desempenho de uma escala analógica visual legendada na determinação do grau de dispneia durante teste de broncoespasmo induzido por exercício em crianças e adolescentes asmáticos. J Bras Pneumol. 2010;36(5):532-8.

34. Mahler DA, Ward J, Waterman LA, McCusker C, Wallack RZ, Baird JC. Patient-reported dyspnea in COPD reliability and association with stage of disease. Chest. 2009;136(6):1473-9.
35. Butcher SJ, Lagerquist O, Marciniuk DD, Petersen SR, Collins DF, Jones RL. Relationship between ventilatory constraint and muscle fatigue during exercise in COPD. Eur Respir J. 2009;33(4):763-70.

36. O’Donnell CR, Schwartzstein RM, Lansing RW, Guilfoyle T, Elkin D, Banzett RB. Dyspnea affective response: comparing COPD patients with healthy volunteers and laboratory model with activities of daily living. BMC Pulm Med. 2013;13:27.

Received in 05/25/2015

Recebido em 25/05/2015

Approved in 06/07/2016

Aprovado em 07/06/2016 